Dieses Dokument ist eine Zweitveröffentlichung (Postprint) /

This is a self-archiving document (accepted version):

Stefan Horlacher

Transgender and Intersex: Theoretical, Practical, and Artistic Perspectives

Erstveröffentlichung in / First published in:

Transgender and Intersex: Theoretical, Practical, and Artistic Perspectives. New York: Palgrave Macmillan 2016, S. 1-27. ISBN 978-1-349-71325-7.

DOI: https://doi.org/10.1057/978-1-349-71325-7 1

Diese Version ist verfügbar / This version is available on:

https://nbn-resolving.org/urn:nbn:de:bsz:14-qucosa2-376392 


\section{Transgender and Intersex: Theoretical, Practical, and Artistic Perspectives}

\section{Stefan Horlacher}

On a hot Berlin summer evening in 2009, 18-year-old Caster Semenya ${ }^{1}$ became the surprise world champion in the 800 meter run by completely outclassing her competitors. Quickly, however, one nagging question came to the forefront: "Is she really a woman?" What followed was a previously unseen and unheard of global media war of speculations surrounding Semenya's 'true' sex, and a discussion that was characterized by complete factual ignorance and incompetence. This case saliently highlights three circumstances: that, even well into the twenty-first century, the existence of exclusively two sexes is still considered to be not only an accepted, but apparently the only acceptable 'scientific fact'; that this supposedly solid assumption should not be challenged; and consequently, that the existence of a socio-biological continuum of sex is still largely ignored and sex diversity suppressed.

What this discussion also, albeit indirectly, made clear was that the twosex model (as well as the prevailing understanding of sex as a unique, innate and immutable characteristic of a human being) is primarily a social construct which causes the oppression, discrimination, and marginalization of all those who cannot conform to these arbitrary principles. Through the sheer fact of their existence, the phenomena of transgender ${ }^{2}$

S. Horlacher

Dresden University of Technology, Dresden, Germany 
and intersex demonstrate that a cultural system that postulates the existence of two, and only two, sexes and genders has reached its limits and that any system that uncritically presupposes an identity between a felt or experienced gender identity and a non-contradictory notion of biological sex must be questioned.

Transgender and intersex studies, which are understood here "as widereaching scholarly undertakings" (Stryker and Aizura 1), are located at the intersections of the humanities and the arts, the social sciences, and the natural sciences. If we wish to understand the construction of transgender, intersex, and other gender identities in their full complexity, fragility, and mutability as well as in their interdependency and interplay with socio-cultural, historical, political and biological factors, trans- and interdisciplinary approaches are absolutely necessary, as is intersectionality. Transgender and intersex studies question not only traditional concepts and binaries, but also our very modes of thinking. By doing so, they pose epistemological and biopolitical ${ }^{3}$ questions; questions that "are ultimately about the categories and concepts we use, about the kinds of knowledge" (Floyd 33) gender studies has produced and the limits to what it can produce. Or, as Judith Butler argues,

the intersexed movement has sought to ask why society maintains the ideal of gender dimorphism when a significant percentage of children are chromosomally various, and a continuum exists between male and female that suggests the arbitrariness and falsity of gender dimorphism as a prerequisite of human development. There are humans, in other words, who live and breathe in the interstices of this binary relation, showing that it is not exhaustive; it is not necessary. $(2006,187)$

In almost the same vein, Cheryl Chase maintains that " $[\mathrm{t}]$ hough the male/female binary is constructed as natural and presumed to be immutable, the phenomenon of intersexuality offers clear evidence to the contrary and furnishes an opportunity to deploy 'nature' strategically to disrupt heteronormative systems of sex, gender, and sexuality" (301). If intersex and transgender are less medically indicated facts (resulting from a supposedly pregiven 'natural' material reality), rather than the product of a culturally constructed, interpreting and evaluating perception (not to say projection or even construction), which is also political, they bring about serious consequences for the socially accepted and legally dominant concepts of masculinity and femininity as well as for feminism ${ }^{4}$ and gender 
studies in general, given that neither masculinity nor femininity can any longer be taken a priori as natural or as the strict province of 'men' or 'women'.

This anthology endeavors to take both transgender and intersex positions into account, and-instead of playing them off against each other-to ask about commonalities and strategic alliances, in terms of knowledge, theory, philosophy, art, and life experience. It intends to strike a balance between work on literature, film, photography, law, sports, and general theory, bringing together humanistic approaches with social science approaches and integrating lenses for studying gender in one book, which would usually rather be found in separate volumes either on intersex or transgender studies. Moreover, this book aims to adopt a non-hierarchical, multiperspective approach that endeavors to overcome the limitations of sex and gender research within the media, disciplines, and fields of studies mentioned above by asking how transgender and intersex issues are negotiated and conceptualized from a variety of different points of view, what specific findings arise from there, and to what extent artistic and creative discourses offer their own uniquely relevant forms of knowledge and expression. For reasons of space and coherence, this book mostly adopts a Western, that is US/European focus, which is supplemented by a chapter on "Transgender in Global Frame" (Chap. 7). Thus, there still remains a lot of research on the global dimensions of transgender and intersex to be carried out (see below) — which might be the subject of a second volume. In addition to the political, social, ethical, legal, biopolitical, and philosophical dimensions covered in this volume, at least six chapters pay special attention to the knowledge that art produces towards a better understanding of transgender and intersex.

Transgender and Intersex: Theoretical, Practical, and Artistic Perspectives was inspired by an international and interdisciplinary conference on "Transgender and Intersex in the Arts, Science and Society" (18-20 January 2012), which I organized at the Deutsches HygieneMuseum Dresden and which was supported by the Dresden University of Technology, the British Council, the Heinrich Böll Foundation, and Dreilinden. I am especially grateful to the British Council who continued to support this project even after the conference with a project grant that made this book possible ${ }^{5}$; a book which is meant to appeal to a wider audience, that is not only to researchers but also to readers familiar with gender studies and feminism, but not necessarily with the concepts of transgender and intersex. Therefore, it seems necessary to define our-more often than not-shifting categories of analysis. However, as I will discuss later, the 
Final edited form was published in "Transgender and Intersex: Theoretical, Practical, and Artistic Perspectives",

New York: Palgrave Macmillan 2016

https://doi.org/10.1057/978-1-349-71325-7_1

differentiation between transgender and intersex is not always clear and a lot more complicated than the binary structure of the following subchapters suggests.

\section{Transgender and Transgender Studies}

As early as in 1999, Jack Halberstam and Annamarie Jagose maintain that

[t]ransgender is for the most part a vernacular term developed within gender communities to account for the cross-identification experiences of people who may not accept the protocols and strictures of transsexuality. Such people understand cross-identification as a crucial part of their gendered self, but they may pick and choose among the options of body modification, social presentation and legal recognition available to them. So, you may find that a transgender male is a female-born subject who has had no sexreassignment surgery, takes testosterone (with or without medical supervision), and lives as a man mostly, but is recognized by his community as a transgendered man in particular. In this context, the term 'transgender' refuses the stability that the term 'transsexual' may offer to some folks, and embraces more hybrid possibilities for embodiment and identification. At the same time ... the term 'transsexual' is undergoing reconstruction... In other words, transsexual is not simply the conservative medical term to transgender's transgressive vernacular; rather, both transsexual and transgender shift and change in meaning and application in relation to each other rather than in relation to a hegemonic medical discourse. (n.pag. $)^{6}$

In their introduction to the first issue of TSQ: Transgender Studies Quarterly, Susan Stryker and Paisley Currah argue that transgender

was meant to convey a nonpathological sense that one could live in a social gender not typically associated with one's biological sex or that a single individual should be able to combine elements of different gender styles and presentations. Thus, from the beginning, the category 'transgender' represented a resistance to medicalization, to pathologization, and to the many mechanisms whereby the administrative state and its associated medicolegal-psychiatric institutions sought to contain and delimit the socially disruptive potentials of sex/gender atypicality, incongruence, and nonnormativity. (2014a, 5)

Thus, transgender can "function as a rubric for bringing together, in mutually supportive and politically productive ways, gender-marginalized 
people in many parts of the world, who experience oppression because of their variance from socially privileged expressions of manhood or womanhood" (8). From this definition of 'transgender', the question arises as to the agenda of the interdisciplinary field of transgender studies. ${ }^{7}$

For Stryker and Currah the field "encompasses the possibility that transgender people...can be subjects of knowledge as well as objects of knowledge. That is, they can articulate critical knowledge from embodied positions that would otherwise be rendered pathological, marginal, invisible, or unintelligible within dominant and normative organizations of power/knowledge" (9). In analogy to fields of intellectual activism such as feminist studies, disability studies, race, and ethnicity studies "and other areas of inquiry that seek to dismantle social hierarchies rooted in forms of bodily difference, the critique of knowledge that operates within transgender studies has an intricate and inseparable connection to broader movements for social justice and social transformation" (ibid.). From this it follows that transgender studies is not merely investigating transgender phenomena as its proper object; "it also treats as its archive and object of study the very practices of power/knowledge over gender-variant bodies that construct transgender people as deviant" (4). Thus transgender studies "is to the medico-juridical and psychotherapeutic management of transgender phenomena what performance studies is to performance, or science studies is to science" (ibid.). As a consequence, transgender studies

does not... merely extend previously existing research agendas... [but] draws upon the powerful contestations of normative knowledge that emerged over the course of the twentieth century from critical theory, poststructuralist and postmodernist epistemologies, postcolonial studies, cultural studies of science, and identity-based critiques of dominant cultural practices emanating from feminism, communities of color, diasporic and displaced communities, disability studies, AIDS activism, and queer subcultures and from the lives of people interpellated as being transgender. (ibid.)

The work of the field, Stryker and Currah further argue, is also to comprehend the nature of past and present shifts in attitudes toward what gender itself means and does, as well as "the new forms of sociality that have emerged from them" (5). Transgender studies thus reevaluates.

prior understandings of gender, sex, sexuality, embodiment, and identity, in light of recent transgender phenomena, from critical perspectives informed 
by and in dialogue with transgender practices and knowledge formations. As historically new possibilities for gender self-perception and expression emerge, as states reevaluate and sometimes alter their practices of administering gender, as biomedical technologies blur customary boundaries between men and women and transform our mode of reproduction, as bodies and environments collapse into one another across newly technologized refigurations of subjects and objects, transgender studies appears [to be] an increasingly vital way of making sense of the world we live in and of the directions in which contemporary changes are trending. (5)

Moreover, transgender studies "engages with the radically transformative implications of contemporary and prospective biomedical technologies of the body". It engages "with critical questions about the boundaries between human and nonhuman animals or between nonliving and living materiality" and discusses "many of the same philosophical questions about the embodied nature of consciousness that arise in the neurocognitive sciences, robotics, and studies of artificial intelligence" $(9) .^{8}$ Recently, Regina Kunzel has argued that one of the most striking new developments in transgender studies seems to be a turn away from identity as a primary object of analysis and a move to critique the notion of a coherent transgender identity or a master narrative of transgender identity formation (see also Valentine).

For Kunzel, transgender denotes less an identity than a way of analysis, an analytical lens, a way of seeing, and a way of knowing that can be understood "as an epistemological position from which new, dissident forms of knowledge are produced" (289). One important field here is the link between colonization/decolonization and transgender, given that transgender studies has been criticized, among other things, for "its implicit whiteness, U.S.-centricity, Anglophone bias" (Stryker and Aizura 4), ${ }^{9}$ given that "the conversation on decolonization in transgender studies has scarcely begun" (Stryker and Currah 2014b, 306) ${ }^{10}$ and that transgender "can operate both as a practice of decolonization that opens new prospects for vitally necessary and radically democratic social change and as a vector for the perpetuation of colonialist practices" (Stryker and Currah $2014 a, 8)$.

Simultaneously, transgender as a field is moving in transnational directions: there are "increasingly globalized transgender studies" (Henry 404), a global approach which explores "how geographic and geopolitical locations and histories of empire, colonialism, displacement, and settlement 
shape different gender-variant subjectivities, identities, and embodiment" (Kunzel; see also Stryker 2006, 14). ${ }^{11}$ Other important developments concern the dialogue between transgender and disability studies ${ }^{12}$ or the ongoing negotiations between transgender and queer studies, given that both fields "are linked through shared histories, methods, and commitments to transforming the situation of gender and sexual outsiders" (Love 172 ) and that " $[\mathrm{c}]$ hallenging discrete categories of identity has been central to the work of both queer and transgender studies from the start" (ibid.). Heather Love argues that while "queer is associated primarily with nonnormative desires and sexual practices, and transgender is associated primarily with nonnormative gender identifications and embodiments, it is both theoretically and practically difficult to draw a clear line between them" (ibid.). ${ }^{13}$ She further argues that queer and transgender studies are linked (a) in their activist investments, (b) their dissident methodologies, (c) their critical interrogation of and resistance to gender and sexual norms, (d) their shared critique of sexual and gender normativity, and (e) in their resistance to disciplinary and methodological norms.

\section{INTERSEX AND INTERSEX STUdies}

While transgender and queer studies are often brought together, this does not hold true for transgender and intersex studies. As Todd Reeser remarks, work on intersex and work in transgender studies are very separate in the broad area of gender studies, and hardly any scholar or scientist works in both areas simultaneously. Given the fact that work in intersex and in transgender studies is still very separate in the broad area of gender studies, one of the aims of this volume is to create a link, to trigger a negotiation between transgender and intersex studies, and to put these two areas of inquiry into closer and more sustained dialogue.

As a matter of fact, it is striking that while the first Transgender Studies Reader did contain work on intersex, namely Cheryl Chase's article "Hermaphrodites with Attitude: Mapping the Emergence of Intersex Political Activism" as well as a second article by T. Benjamin Singer, which at least took intersex into consideration, there are only three entries in the index for intersex in the Transgender Studies Reader 2 (pages 157$60,389,391-2)$, the biggest of which refers to an article about "Animal Trans" and discusses, among other things, the fact that "barnacles can be intersex" (Hird 158). The relation between intersex studies and feminism is also problematic and tenuous: Cheryl Chase argues that intersex queers 
"the foundations upon which depend not only the medical management of bodies but also widely shared feminist assumptions of properly embodied feminine subjectivity. To the extent that we are not normatively female or normatively women, we are not considered the proper subjects of feminist concern" (312). ${ }^{14}$ The picture also is bleak with regard to the relation between intersex studies, politics, medicine, and biology. Here, Chase blames "the complex interactions between ideologies of race, gender, colonialism, and science" which "effectively silence and render invisible intersex experience in first-world contexts" (310). ${ }^{15}$ For her, "[c]utting intersex genitals becomes yet another hidden mechanism for imposing normalcy upon unruly flesh, a means of containing the potential anarchy of desires and identifications within oppressive heteronormative structures" (ibid.). But maybe we should go one step back and start with a definition of intersex:

Sometimes individuals are born with genital, genetic, or hormonal characteristics that some people find confusing. From this phenomenon of 'intersex,' a range of claims and counterclaims have flowed regarding sexual difference, medicine, gender, and identity ... Intersex is often popularly conflated with ambiguous genitalia-external sexual anatomy that cannot be easily described as entirely female or male... However, for clinicians, an intersex diagnosis can refer also to attributes that are not apparent on the body's surface, including XXY sex chromosomes or indifference to the hormones that produce effects connotative of masculinity. What such intersex diagnoses have in common is the medicalization of a failure to classify the body as one of two sexes. That such a failure would be problematic is not obvious, nor is its medicalization; nonetheless, medical treatment of intersex is standard practice in the West... Within the last decade, medical guidelines have shifted to recommend psychological support and disclosure by default..., but the extent to which these guidelines have been put into practice remains disappointingly unclear. (Morland 111) ${ }^{16}$

Iain Morland argues that "to this day, medical sexology remains largely disengaged from relevant debates in the humanities over gender and the constitution of the self" and that "the medicalization of intersex is a fundamentally erroneous project" which "mistakes social norms and their transgression for properties of bodies, which can be modified or disambiguated through clinical interventions. But ambiguity is an interpretation, not a trait; and one cannot do surgery on a norm" (113). ${ }^{17}$ In this sense, Chase argues that "current medical practice effectively abolishes the natural 
diversity of sexed body types and uses the sharp end of a scalpel to impose a culturally constructed male/female dichotomy" (300). More than 25 years ago, Suzanne Kessler noted that "the possibilities for real societal transformations would be unlimited" if only physicians and scientists specializing in the management of gender could recognize that

finally, and always, people construct gender as well as the social systems that are grounded in gender-based concepts ... Accepting genital ambiguity as a natural option would require that physicians also acknowledge that genital ambiguity is 'corrected' not because it is threatening to the infant's life but because it is threatening to the infant's culture. (Kessler qtd. in Chase 313)

Because our culture has "relinquished to medicine the authority to police the boundaries of male and female", intersexuals are left "to recover as best they can, alone and silent, from violent normalization" (Chase 303). In order to get beyond this silence and marginalization, we have to recognize that "intersex, transgender, and sexual-orientation activism are closely linked through a shared liberal emphasis on protecting personal ethical choice and the right to control one's own body" (300). As Morland argues, in

the context of trans studies, both intersex and transsexuality raise the question of what kind of body one needs to have in order to claim membership in a gender and whether a person's sense of belonging to a gender is colored by the experience of living in a body that has been touched by medical technology. Sometimes intersex and transsexuality have been construed as complementary examples of gender's construction-where the former shows gender's assemblage by force, and the latter its alteration by free will. But that analysis assumes the success of most intersex treatment and fails to account for the continuity of identity experienced by many trans individuals before and after medical treatment. Encounters with medicine neither cause trans people to change gender nor cause intersex individuals to acquire gender in the first place. (114)

If intersex and transgender communities are socially marginalized because they belie the core contemporary ideology that people are born with a binary physical sex, and that this determines their binary gender, we have to inquire into who profits from the rigid maintenance of this binary system. By doing so, the hierarchical structure of scientific disciplines or discourses which deal with transgender and intersex has to be taken into 
account. Which discourses claim to have the prerogative of interpretation, that is, the right to define and to interpret these phenomena or varieties? Why has Western culture relinquished the authority to police the boundaries of sex and gender to discourses such as biology and medicine? How do these discourses justify their claims to authority, and why-given that there are many human beings who do not fit into the culturally produced, traditional, heteronormative system of being either male or female-does Western culture, even in the twenty-first century, still vigorously defend this system of enforced binaries? And finally: How is this regime linked to the constitution, the law, and the organization of society in general?

\section{Opposing Frameworks, Possible Paradoxes, AND ESSENTIALISMS}

By bringing up the questions mentioned above, transgender and intersex studies can be seen as forms of critical knowledge engaged in an epistemological and biopolitical battle; as "insurgent knowledges" that "challenge official knowledges" (see Stryker 2006, 12-13), such as the male/female binary, a category which is enforced not only on the public and individual consciousness, but also on the body. In this context, Sarah Creighton argues:

One dilemma is that I feel to some extent pressured by two clearly opposing views. On one side is the belief held by most adult support groups that genital surgery is often harmful and that genital variation and difference are valuable and acceptable.

On the other side is the constant pressure by society that difference is a bad thing and that all must aspire to a 'normal' appearance. Patients are often deeply influenced by the latter, which drives and informs decisions they make about surgery for themselves or for affected children. (253; see also Chap. 2 by Whittle and Turner in this book)

What has become evident in this quote is the contrast between what Cary Gabriel Costello, in his chapter in this book, calls "an identity framework" and "a disorder framework". Very often, these two frameworks not only lead to rifts within both intersex and transgender communities, but also explain some of the problems and misunderstandings between these communities. Both the intersex and transgender communities contain individuals who frame their community distinction as a matter of identity 
and pride, and others who view their difference as a disorder that should be approached with pity and cured medically. As Costello argues, many transsexuals present transsexuality as an intersex condition of the brain, their hope being that if the larger society can be persuaded that this is the case, medical transition services will be freely provided out of pity to cure those afflicted with intersex brains, as children with intermediate genitals are given sex assignment surgery. ${ }^{18}$

If the focus on the relation between transgender and intersex communities as well as their marginalization by society is an important aspect of this volume, another is - on a more philosophical or abstract levelthe problem of the recurrence or reappearance of what could be called 'body essentialism' on the one hand, and 'mind essentialism' (see Chaps. 5 and 9) on the other-with the added twist that some theories, almost paradoxically, locate the primacy of the mental structure in biology. ${ }^{19}$ While Alice D. Dreger and April M. Herndon contend that "even hard-core constructivism amounts to an essentialism itself-in this case, actually a biological essentialism that presumes everyone is born with a blank slate for a brain where gender is concerned" (216), Anne Fausto-Sterling points out that "on close inspection, absolute dimorphism disintegrates even at the level of basic biology. Chromosomes, hormones, the internal sex structures, the gonads, and the external genitalia all vary more than most people realize" $(2000 \mathrm{~b}, 20) .{ }^{20}$

In fact, neither a hard-line social constructivist nor a hard-line biological essentialist theory of gender seems supportable by the real-life experience of people with intersex ... Ultimately it seems illogical to have so firm a belief in either the biological determination or social construction of gender that all of us with stable identities amount to either biologically programmed robots or victims of false consciousness. (Dreger and Herndon 215-6) ${ }^{21}$

From this it follows that both body and mind essentialism are not only potentially self-contradictory, but also run the risk of reductionism. These forms of essentialism probably reveal more about the reliance of the human mind on binary structures and relations in understanding and making sense of a multifaceted and polymorphous reality than about this reality itself. Here again, the supposed difference between femininity and masculinity, between sex and gender, and between nature and culture is shown to be untenable, given that "the only way we can ever access the supposed hard truth of the material body is through the same 'constructed' cat- 
egories from which we also seem, persistently, to want to distinguish that body" (Floyd 33-4). If Chase argues that in a two-stage process science "produces through a series of masked operations what it claims merely to observe" (303) then the male/female binary-just as other binaries-is a prime example of this and the "result of the very medical technologies designed to enforce it" (Floyd 40).

Our conceptions of the nature of gender difference shape, even as they reflect, the ways we structure our social system and polity; they also shape and reflect our understanding of our physical bodies. Nowhere is this clearer than in the debates about the structure (and restructuring) of bodies that exhibit sexual ambiguity. (Fausto-Sterling 2000a, 45)

Sandy Stone has called the transsexual body "a hotly contested site of cultural inscription, a meaning machine for the production of ideal type" (230). She argues that it is exactly on the battlefield of the transsexual body that the "epistemologies of white male medical practice, the rage of radical feminist theories and the chaos of lived gendered experience" (ibid.) clash. But is the trans * body really "futurity itself” (Halberstam 2005, 18), as some would claim, making male pregnancies possible (see Chap. 6 by Stritzke and Scaramuzza in this book) and paving the way to technotopias, to bodies with new organs and to organs without bodies? ${ }^{22}$ And how do we conceive of the body? As a Lacanian system of differences (see Horlacher $2010,221-32$ ), as a biopolitical or 'merely' as a biological entity and a new playground for cosmetic surgery (see Atkinson 2006, 2008), as être brut or raw being in the sense of Merleau-Ponty, as "one (already constituted) object of knowledge among others", as "the contingent ground of all our knowledge, and of all our knowing” (Stryker 2006, 12; see also Fuss 254) or as the unreachable and finally unknowable product of cultural categories? Has the body really "remained a conceptual blind spot in both Western philosophical thought and contemporary feminist theory" as Elizabeth Grosz argues (3), ${ }^{23}$ while the "materiality of language in contemporary thought has taken the place of the materiality of the body" (Prosser 13)?

While Jay Prosser argues that in "transsexual accounts transition does not shift the subject away from the embodiment of sexual difference but more fully into it" (6), ${ }^{24}$ and while he asks whether there are not also "transgendered trajectories... in particular transsexual trajectories", in the sense of "transsexuals who seek very pointedly to be nonperformative, to be constative, quite simply to $b e$ " (32, emphasis in the original), we could 
ask whether transgender/transsexual automatically implies a change from one discrete gender/sex to another and whether trans* should not be understood "as a transition toward movement itself", so that "the trans body might destabilize stable definitions of femininity and masculinity by inventing new gendered configurations" (Reeser 33). Maybe it is precisely "[b]ecause the transition is so frequently not into the comfortably knowable space of maleness or femaleness, but into a gendered space that remains inconceivable" that "the challenge transgender and intersex studies present" to gender studies, science and society in general "is a challenge to what the available terms of this area of study" but also the ideas, concepts and configurations floating in the cultural imaginary and the cultural unconscious "allow us to conceive, and to what they hinder us from conceiving" (Floyd 46). ${ }^{25}$

\section{The Creative Dimension, or: The Arts as Repository of THE Cultural Imaginary}

One of the most important sources of knowledge, where the unthinkable becomes thinkable, where horizons can be transgressed, and where resistance is possible is the arts. Therefore, it is absolutely necessary to take the specific knowledge of the arts into account, first, by considering them as indispensable epistemological media as well as important objects of research; second, by focusing on the complex interactions between Lebenswelt and the arts; and third, by paying close attention to the important role the arts play in acquiring a knowledge of the lifeworld, that is, a knowledge about and for living different lives (see Ette 2010) that renders Überleben (survival) possible (see Ette 2004). While art surely takes part in the regulating functions detailed by Michel Foucault, it also just as surely has the power to resist ( see Ostrov Weisser 11), can be considered as a repository of culturally and socially relevant knowledge and hence as a privileged medium of analysis (see Horlacher 2013, 1-15).

Literature, photography, film, and other art forms can be understood as phenomena that actively shape extra-textual reality, constitute a central part of that "larger symbolic order by which a culture imagines its relation to the conditions of its existence" (Matus 5), expose as well as delineate "ideologies, opening the web of power relations for inspection", and constitute a space "in which shared anxieties and tensions are articulated and symbolically addressed" (7). The arts hold a knowledge 
or savoir littéraire (in the wider sense) which transcends any purely sociological, political, or historical analysis (see Horlacher 2004; 2008), and represent a privileged space of simulation where the work they perform on a broader cultural imaginary can be analyzed (see Fluck 1997, 7-29; Horlacher 2006; 2008).

Therefore, the critical analyses offered in this volume should make it possible not only to identify the mechanisms of construction and transformation of gender identities within works of art, understood as highly artificial, condensed, polysemous symbolic systems, but also to relate their internal logic or mechanisms to both the artistic system itself and the wider social and cultural context. This consideration of contemporary art (and its link to activist movements and politics) is of special importance since, according to scholars ranging from Stephen Greenblatt via Roland Barthes to Donald Winnicott, Wilfried Fluck, and Georg Simmel, art creates spaces in which ludic, creative, and experimental thinking becomes possible, in which humankind can transcend itself and create new ways of living and alternative concepts of understanding, also of one's own gender or sexual identity.

Since it is through the individual person that art exercises its influence on society and its notion of community, and since transgender and intersex are primarily social/cultural issues and phenomena, the interdependency and interaction between art, the individual, and society is of prime importance. Art has not only made identity one of its most important themes, but through its very functioning plays a significant role in the construction of the identity of its readers, viewers, and listeners. The value of art and, as Jonathan Culler argues, especially literature, has "long been linked to the vicarious experiences it gives readers, enabling them to know how it feels to be in particular situations and thus to acquire dispositions to act and feel in certain ways" (113).

Not only literary works but also other art forms, such as film, photography, and theater, etc. "encourage identification with characters by showing things from their point of view" (ibid.). They "address us in ways that demand identification, and identification works to create identity: we become who we are by identifying with figures we read about"; figures who create different, alternative, and novel identities (114). ${ }^{26}$ Thus, art has the (political) power to interrupt the foundational narratives dominant in any particular society or community and pave the way for "other divergent or emergent narratives, or new and different forms of sense" (James 199). It possesses the "power of ontological disclosure" (200), 
interrupting myths of completeness, closure, and homogeneous totality. Moreover, art is particularly suited to communicate shared existence as such and to expose that "community exists always and already ... as the nonidentity of shared finitude" (James 197; see Nancy) because the inherent polysemy of art illustrates and "affirms a sharing of sense which is irreducible to any fixed identity or meaning" (James 200). Art thereby reveals the heterogeneity of any society or community and actively gives voice to marginalized and minoritarian groups and discourses.

Works of art are not only characterized by their ability to defamiliarize and alienate; and do not only subvert "the illusions on which our perception is based" by opening up "an unexpected view of the object" and by thus drawing "attention to the illusory nature of conventional modes of perception", ${ }^{27}$ but also generate acts of the imagination which involve ideation (Vorstellung) instead of perception (Wabrnehmung). By thus conceptualizing the act of reading (understood in a wider sense) as an act of imagining, we can stress the potential not only of the fictional text but also of other art forms "to articulate something that is still unformulated" (Fluck 2002, 257) and to give "a determinate shape to imaginary elements, ranging from fantasy to affective dimensions, by linking these elements with a semblance of the real" (261). The aesthetic experience can thereby be understood as “a state 'in-between' in which, as a result of the doubling structure of fictionality, we are ... 'both ourselves and someone else at the same time" (263). The act of fictionalizing does thus appear as "a constant crossing of boundaries between the real and the imaginary" (Iser 1986, 5) whereby the imaginary is endowed with a determinate gestalt while "reality's determinacy is outstripped" (ibid.). Thus, "[e]nabled by acts of fictionalization to move constantly between the imaginary and the real" (Thomas 626), readers (of books, paintings, films, and so on) perpetually 'stage' themselves, fashion new identities, imagine new worlds and create other, more expressive versions of themselves; versions of themselves which are not simple cases of self-aggrandizements "through wish-fulfillment but an extension of [their]... own interiority over a whole (made-up) world" (Fluck 2002, 263-4).

From this, it follows that by creating a fictional account of a diffuse imaginary without direct reference to extra-textual reality, art and-given the overall importance of language and its performative dimension for what it means to be human-especially literature can be regarded as a particularly effective medium for the creation of alternative selves beyond what is deemed acceptable within a specific culture. In doing so, it enables 
the human being to continuously transcend itself and opens up new leeway for imaginary constructions of the self while producing the simultaneous existence of the possible and the real. It is this simultaneity that renders art a privileged medium for working on a cultural imaginary that not only offers the individual a wealth of possibilities, but also motivates said individual to express, stage, and invent itself in ever original and novel acts (see Fluck 1997, 7-29). And in the context of the premises which guide the present volume, this means-above all-the creation of ever new and different gender or sexual identities and subject positions.

\section{Topics, Chapters, Structures}

One aim of this volume is to make sure that the literary texts, films, photographs, etc. chosen for the following analyses are highly topical and representative of the ongoing de- and reconstruction of transgender, intersex, and other gender identities during the late twentieth and early twenty-first centuries, and to precede these analyses with a group of more theoretical articles which explore fundamental legal, sociological, and lifeworld perspectives. Given the importance and regulatory function of the law in Western societies, it should be no surprise that the first two chapters in this volume focus on legal questions in relation to transgender and intersex. Chapter 2 by Stephen Whittle and Lewis Turner on "Queer Europe: New Normative Values for Global LGBT Law" not only reviews the jurisprudence of sex and gender in medieval Europe-a history in which a JudeoChristian based legal framework allowed for the persecution and judicial killing of LGBT people-but also considers how the new 'Europes' of the European Union (EU) and the Council of Europe, in their response to a Europe in which the Nazi genocide was able to flourish, have responded to this traditional jurisprudence. The chapter outlines the development of a new moral sensibility, a new 'rule of law', which has created a social and legal framework in which LGBT people's rights have not just been increasingly recognized, but are also increasingly protected.

Chapter 3 deals with legal frameworks in sports. In "Fear, Loathing, and Empty Gestures: UK Legislation on Sport and the Transgender Participant" David McArdle argues that the Gender Recognition Act 2004, s.19-which sought to restrict transgendered persons' opportunities to participate in sports-was never argued before the courts of the UK before being repealed by the Equality Act 2010, and that the 2004 Act had sought to ban transgendered persons' sports participation if their 
involvement was not conducive to either 'competitive fairness' or 'safety'. His chapter explores the legal difficulties that were always bound to exist in enforcing a prohibition on either ground, and considers the relevant medical literature and fundamental legal principles that are common to most European jurisdictions. By doing so, McArdle illustrates the difficulty of introducing lawful, effective constraints on transgender participation, and argues in favor of inclusivity for all sports participants.

The following three chapters all focus on transgender and intersex simultaneously: Chapter 4 by Cary Gabriel Costello on "Intersex and Trans* Communities: Commonalities and Tensions" shifts the focus from a legal to a more sociological or 'real life-perspective'. Costello maintains that intersex and trans* communities are similar in that they are both marginalized because they belie a core contemporary ideology, that is that people are born with a binary physical sex, and that this determines their binary gender. Costello argues that trans* and intersex people, having bodies and identities that often conflict with this precept, are subjected to social stigma that can have powerful negative effects. While this commonality has led some intersex and trans* people to make common cause and work together politically, other factors, which Costello analyzes in detail, drive the two communities apart. He concludes that it is only the subsets of the intersex and trans* communities that employ what he calls an "identity framework", who tend to work together as allies. These allied individuals center the idea that sex status should be a matter of personal autonomy based on gender identity, and validate non-binary gender identities in addition to binary ones.

Chapter 5 by Sebastian Jansen on "Transgender and Intersex: Unavoidable Essentialism and the Normative Struggle for Recognition" takes Costello's observations into account but argues on a more theoretical and abstract level. According to Jansen, transgender and intersex studies are stuck in an 'anti rhetoric' against heteronormativity and binary oppositions. Not only is this practice, he argues, questionable from a theoretical point of view, but, much more problematically, it serves to alienate parts of the community-most notably many intersex people. In order to find new ways of formulating activism, Jansen interrogates the theoretical underpinnings of transgender and intersex studies respectively. What emerges are two persistently recurring forms of essentialism: 'mind essentialism' and 'body essentialism'. But instead of denouncing them, Jansen shows how essentialisms can be employed for emancipatory positions-a strategy that has further implications for transgender and intersex stud- 
ies and their contributions to gender studies in general. Finally, Jansen proposes a shift away from fighting against a binary gender system in gender studies towards working for intersex and trans* people's recognition and self-determination-tacitly accepting that this may change the gender framework as we know it.

In Chapter 6, "Trans*, Intersex, and the Question of Pregnancy: Beyond Repronormative Reproduction", Nadyne Stritzke and Elisa Scaramuzza argue that reproduction in Western societies remains a cultural realm which is distinctively governed by characteristically heteronormative discursive conditions and that-because of this-it is high time to critically examine the interrelatedness between repronormativity and trans* and intersex lived bodies. They contend that Western cultures are moving towards paradigmatic changes of legalizing, treating and embodying sex/gender identities that will substantially alter socio-cultural discourses on, and practices of, reproduction. Within this period of upheaval, the question of trans* and intersex pregnancies challenges norms of reproduction, with both trans* as well as intersex pregnancies being perceived, or better, constructed as deviations from a hegemonic binary norm. In the last part of their chapter, Stritzke and Scaramuzza delineate significant new perspectives on how repronormatively organized discourses form the basis of our cultures' understanding of trans* and intersex pregnancies and emphasize their shared characteristics in order to develop mutual political strategies.

In Chapter 7, “Transgender in a Global Frame”, Jack Halberstam discusses the subtle discursive shifts which have made transgenderism in the USA and Europe into simultaneously a mark of the historically specific definitional cleaving of homosexuality from gender variance, a trendy and stylistic shift from gender androgyny within lesbian communities to gender variance within gender-queer communities, and a sign of an internal split within feminism between the stabilization of the category of woman and the undermining of the coherence of the category within queer theory. Halberstam demonstrates how transgenderism has been installed within a 'global gay' system as part of the hegemony of US taxonomies - the addition of ' $\mathrm{T}$ ' to the acronym 'LGBT' allows for the neat division and explanation of a very wide range of translocal phenomena in terms of the US model. For Halberstam, this leads to the question as to how we are to understand and explain the impact of transgenderism upon, not only traditional gendering, but also upon queer communities and even on the ebb and flow of sexual and gender definition globally. 
The first chapter dedicated to the arts in this volume can, in itself, be considered a work of art. "INTER*me: An Inter-Locution on the Body in Photography" is a contribution written by Jay Prosser, Eliza Steinbock, and photographer, 'part time gender terrorist', and twice-parent ('Ma-Pa') Del LaGrace Volcano. It features many up-to-now unpublished photos by Volcano and engages, as the title suggests, on herm's latest photographic series, titled INTER *me. The 'inter-locution' in form of a conversation with friends and fellow gender travelers interleaves Volcano's most recent images with some of herm's earlier iconic photographs, as the discussion reflects on various interstices: between the body, aging, and cultural ideals of beauty; between self-imaging, community representation, and familial connections; and between the technologies of gender and those of photography. The conversation reveals how the patterns in the INTER *me series interlock with those in Volcano's oeuvre and ultimately also with the interwoven patterns of birth, life, and death.

Following Volcano's, Prosser's, and Steinbock's contribution, Chapter 9 comprises almost all realms this book is concerned with. In his article on "Hermaphrodite's Voice: Dealing with the Either-Or Attitude in Science, Law and the Arts", Michael Groneberg situates resistances against the acceptance of what he calls "inter- and transgendered persons" in the "eitheror attitude' governing human mind and action by a disjunctive logic, and discusses possible solutions. Groneberg identifies the 'either-or attitude' in the tendency of science to create binary analytic tools as well as in antique forms of art production, and demonstrates how sex/gender and nature/ nurture distinctions reproduce a disjunctive attitude with violent potential on the level of theory. Stressing the importance of the arts and the imaginary, Groneberg draws in a tour de force on Greek statues, on texts by Ovid and Plato, on German and French literature (Mitgift, Le clavecin, La tête en bas, Sarrasine), on John Cameron Mitchell's musical Hedwig and the Angry Inch, and on Del LaGrace Volcano's photography. He concludes by arguing that the various ways different art forms deal with irruptions of the gender binary offer highly valuable insights into the actual challenges of modern life and also of science and the arts.

Chapter 10, by Mirjam M. Frotscher, also stresses the importance of the arts and brings, once again, transgender and intersex together. In "On the Intelligibility of Trans* and Intersex Characters in Contemporary British and American Fiction", Frotscher argues that the past decades have seen an unmistakable uptick in fiction starring trans* or intersex characters and that their entrance into fictional space can potentially open up new narra- 
tive possibilities in representing characters who were, and sometimes still are, deemed hard to portray or seen as entirely unintelligible. Focusing on three novels in particular, Stone Butch Blues (1993) by Leslie Feinberg, Trumpet (1998) by Jackie Kay, and Middlesex (2002) by Jeffrey Eugenides, Frotscher traces the different modes of representation used in the novels, the way all three differ in their approach to their trans* and intersex protagonists, and the concepts of gender, sex, and sexuality underlying these narratives. Finally, she inquires to which degree the trans* and intersex lives presented are deemed viable and intelligible.

In the final chapter (Chap. 11) of this volume, John Phillips' "Boys Don't Cry and Tomboy: A Comparative Analysis", the different media and art forms analyzed so far are supplemented by film, the principal focus being a French movie, Tomboy (2011), viewed and interpreted intertextually through the prism of an earlier English-language film, Boys Don't Cry (1999). Phillips' discussion draws on the relevant discourses of queer theory, principally the work of Judith Butler, and on appropriate Freudian and Jungian ideas, and argues that both films address the theme of crossdressing and its effects on others, showing that the emotional and psychological reactions of close adults can have equally traumatic effects in the case of children as in that of teenagers. Both films therefore represent, as Phillips demonstrates, a plea for the understanding of transsexual tendencies, regardless of the age concerned, while raising questions relating to sexual maturity and the rights of the individual.

\section{Notes}

1. For reasons of space, I limit myself to this example taken from the field of intersex. As far as transgender is concerned, other examples could have been given, the most salient being Chelsea Manning, Caitlyn Jenner or Lana Wachowski.

2. In the different chapters of this book, the terms or concepts of trans*, transgender and transsexual are used since I did not want to impose categories or restrictions on the authors of the different chapters. In this introductory article, I use the term transgender as umbrella term; transsexual is only used if the bodily dimension is stressed, that is when the fact that people have undergone surgery is of significance. Moreover, whenever secondary literature is quoted, discussed or commented on in this introduction, I also use the original terms. For the usage of transgender as 'umbrella term' see Stryker and Aizura, who call “transexual, transvestite, transgender, and genderqueer" alternate spellings of "transsexual" (2); Williams, 
who claims that the "word transgender entered widespread use as an umbrella term for describing a range of gender-variant identities and communities" (232), and Love, who argues that transgender is "able to conjure a spectrum that can include transsexuals, cross-dressers, and butches and femmes" but "also signals a resistance to the taxonomic framework implied by the model of the spectrum (even as it 'overcomes' it)" (173). For the emergence and institutionalization of transgender as a category of collective identity and political activism see Valentine.

3 . The term biopolitical is used here in a Foucauldian sense. See Foucault (2012), Stryker (2014, 38-42).

4. For a critical analysis of the relationship between feminist studies and transgender studies see Enke (2012); Heyes, and especially Noble.

5. I would also like to thank Sebastian Jansen (TU Dresden), Ulrike Kohn (TU Dresden), and Mirjam Frotscher (TU Dresden) for their help with the manuscript as well as Todd Reeser (Pittsburgh) and Bill Baker (Ohio State) for their support.

6. See also Williams; Stryker and Currah (2014a, 1-18).

7. See also: TSQ: Transgender Studies Quarterly, of which volume 1.1-2 (2014) offers a survey of "key concepts" for trans* studies; Stryker and Whittle; Stryker and Aizura; McKenna and Kessler.

8. "As such, transgender studies is emerging as a vital arena for exploring the evolving edge of our species-life at a historical moment of rapid technological and environmental change that calls into question some of our most fundamental notions of what human life means and may come (or cease) to be" (Stryker and Currah 2014a, 9). See also Halberstam (2005): "Transgenderism, with its promise of gender liberation and its patina of transgression, its promise of flexibility and its reality of a committed rigidity, could be the successful outcome of years of gender activism" (21). However, as Halberstam also concedes, it could just as easily be "the sign of the reincorporation of a radical subculture back into the flexible economy of postmodern culture" (ibid.).

9. Kunzel argues that transgender identity may raise "problems of false coherence that flatten out differences among transgender subjects, of required conformities for recognition as authentically transgender, of the implicit whiteness and middle-classness of the transgender subject" (288). Stryker and Currah (2014a) admit that, given the fact that the term transgender "originated among white people within Eurocentric modernity ... it risks becoming yet another project of colonization ... for making sense of human diversity by measuring it within a Eurocentric frame of reference, against a Eurocentric standard" (8).

10. It is in this context that Stryker and Aizura pose the question of what "kinds of questions and practices, then, can transgender studies offer that advance an anti-colonialist agenda, and that resist the subsumption of non- 
western configurations of personhood into western-dominant frameworks that privilege either 'homo' or 'trans,' or assume the ontological given-ness of the concepts man and woman? What might an anti-colonial or decolonizing transgender studies look like?" (9) See also: Feminist Studies 37.2 (2011).

11. See also the special issue "Decolonizing the Transgender Imaginary." TSQ: Transgender Studies Quarterly 1.3 (2014).

12. For a dialogue with disability studies see: Enke (2013); Clare.

13. See also Stryker and Currah (2014a) who argue that a "particularly rich stream of dialogue within transgender studies pertains to the relationship between transgender and queer" (6).

14. "Intersexuals have had such difficulty generating mainstream feminist support not only because of the racist and colonialist frameworks that situate clitorectomy as a practice foreign to proper subjects within the first world but also because intersexuality undermines the stability of the category 'woman' that undergirds much of first-world feminist discourse. We call into question the assumed relation between genders and bodies and demonstrate how some bodies do not fit easily into male/female dichotomies. We embody viscerally the truth of Judith Butler's dictum that 'sex', the concept that accomplishes the materialization and naturalization of powerladen, culturally constructed differences, has really been 'gender' all along" (Chase 312).

15. "About one in a hundred births exhibits some anomaly in sex differentiation, and about one in two thousand is different enough to render problematic the question 'Is it a boy or a girl?'” (Chase 300). From a medical perspective, among the most common types of intersex are congenital adrenal hyperplasia (CAH), androgen insensitivity syndrome (AIS), gonadal dysgenesis, hypospadias, as well as chromosome compositions such as XXY (Klinefelter Syndrome) or X0 (Turner Syndrome).

16. Intersex activists and a vast majority of critics rightly argue that surgery on intersex babies should wait until the child can make an informed decision and consider surgery without consent as genital mutilation. For a more detailed discussion of intersex see: Karkazis; Fausto-Sterling (2000a, b); Butler (2006); Hughes; Dreger and Herndon; Dreger; Deutscher Ethikrat.

17. "Further, the efforts by clinicians and families to eliminate intersex have traditionally entailed the strenuous production of silences-about hospital visits, scars, parental fears, injections, and even years of childhood-that actively create intersex as a state of strangeness rather than securing its removal from discourse. The experience of treatment as simultaneously objectionable and ineffective has been a central complaint of the intersex rights movement since its inception in the early 1990s"..." Consequently, activists have reappropriated intersex as an identity. To identify as intersex, 
is to assert both that treatment does not work, insofar as medical interventions amplify the strangeness of one's intersex attributes, and that treatment should not be done at all, insofar as it discriminates against individuals on the basis of immutable characteristics" (Morland 113; see also Chase).

18. It should be mentioned that in contrast to this, intersex individuals largely resist the idea that trans* status is an intersex condition of the brain, and that this tension often drives the two communities apart.

19. See Garcia-Falgueras and Swaab; Zhou, Hofman, Gooren and Swaab; Whittle xiii; Dreger and Herndon 211-3.

20. For a different form of biological essentialism see Garcia-Falgueras and Swaab.

21. See also Fuss; van den Berg.

22. One should also ask here how trans* does relate to gender neutrois, to agender or nonbinary people.

23. See also Prosser: "A glance at any number of new titles shows bodies are everywhere in contemporary cultural theory; yet the paradox of theory's expatiation upon bodies is that it works not to fill in that blind spot so much as to enlarge it" (12).

24. See also Whittle, who argues that "many non-trans theorists have used trans identities to support constructivist arguments. But increasingly, trans people are questioning whether the deeply held self-understandings they have can be entirely due to nurture and environment" (xiii).

25. Therefore, we must ask whether the current approaches in gender studies are not on the side of normalizing knowledges and how-akin to Stryker's claim for transgender studies $(2006,13)$-gender studies in all its different branches can, and indeed should, endeavor to become a critical intervening force that questions biopolitical norms and implicit conventions by helping spark what Foucault has called an 'insurrection of subjugated knowledges'. See also: Windschuttle; Floyd.

26. See also Iser who stresses more generally that art enables us to grasp the notion of identity because identity escapes cognitive conceptualisations and can only be experienced. Therefore, any conceptualisation of identity possesses a strong affinity with art.

27. Iser qtd. in and translated by Fluck $(2002,256)$.

\section{Works Cited}

Atkinson, Michael. "Exploring Male Femininity in the 'Crisis': Men and Cosmetic Surgery." Body \& Society 14.1 (2008): 67-87.

. "Masks of Masculinity: Cosmetic Surgery and (Sur)passing Strategies." Body/Embodiment: Symbolic Interaction and the Sociology of the Body. Ed. Dennis Waskul and Phillip P. Vannini. London: Ashgate, 2006. 247-61. 
Final edited form was published in "Transgender and Intersex: Theoretical, Practical, and Artistic Perspectives",

New York: Palgrave Macmillan 2016

https://doi.org/10.1057/978-1-349-71325-7_1

Butler, Judith. "Doing Justice to Someone: Sex Reassignment and Allegories of Transsexuality." Stryker and Whittle 2006. 183-93.

- Gender Trouble: Feminism and the Subversion of Identity. 1990. London: Routledge, 2008.

Chase, Cheryl. "Hermaphrodites with Attitude: Mapping the Emergence of Intersex Political Activism." Stryker and Whittle 2006. 300-14.

Clare, Eli. "Body Shame, Body Pride: Lessons From the Disability Rights Movement." Stryker and Aizura 2013. 261-65.

Cromwell, Jason. "Queering the Binaries: Transsituated Identities, Bodies, and Sexualities." Stryker and Whittle 2006. 509-20.

Culler, Jonathan. Literary Theory: A Very Short Introduction. Oxford: Oxford UP, 1997.

"Decolonizing the Transgender Imaginary." TSQ: Transgender Studies Quarterly 1.3 (2014). Special Issue.

Deutscher Ethikrat, ed. Intersexualität. Stellungnabme. 23 Feb. 2012. Web. 9 June 2015. http://www.ethikrat.org/dateien/pdf/stellungnahme-intersexualitaet.pdf.

Dreger, Alice Domurat, ed. Intersex in the Age of Ethics. Hagerstown: University

Publishing Group, 1999.

Dreger, Alice Domurat and April M. Herndon. "Progress and Politics in the

Intersex Rights Movement. Feminist Theory in Action." GLQ: A Journal of Lesbian and Gay Studies 15.2 (2009): 199-224.

Enke, A. Finn. "The Education of Little Cis: Cisgender and the Discipline of Opposing Bodies." Stryker and Aizura 2013. 234-47.

- ed. Transfeminist Perspectives In and Beyond Transgender and Gender Studies. Philadelphia: Temple UP, 2012.

Ette, Ottmar. "Literature as Knowledge for Living, Literary Studies as Science for Living." PMLA 125.4 (2010): 977-93.

—. ÜberLebenswissen: Die Aufgabe der Philologie. Berlin: Kadmos, 2004.

Fausto-Sterling, Anne. Sexing the Body: Gender Politics and the Construction of Sexuality. New York: Basic Books, 2000a.

—_. "The Five Sexes Revisited." The Sciences 40.4 (2000b): 19-23.

33.2 (1993): $20-5$.

Floyd, Kevin. "Masculinity Inside Out: The Biopolitical Lessons of Transgender and Intersex Studies." Horlacher 2011. 33-48.

Fluck, Winfried. "The Role of the Reader and the Changing Functions of Literature: Reception Aesthetics, Literary Anthropology, Funktionsgeschichte." European Journal of English Studies 6.3 (2002): 253-71.

- Das kulturelle Imaginäre. Eine Funktionsgeschichte des amerikanischen Romans 1790-1900. Frankfurt/Main: Suhrkamp, 1997. 
Foucault, Michel. "The Mesh of Power." Viewpoint Magazine. Viewpointmag, 12 Sept. 2012. Web. 13 Sept. 2014. https://viewpointmag.com/2012/09/10/ issue-2-theory-and-practice/.

Fuss, Diana. "The 'Risk' of Essence." Feminisms. Eds. Sandra Kemp and Judith Squires. Oxford: OUP, 1997. 250-58.

Garcia-Falgueras, Alicia, and Dick Swaab. "Sexual Hormones and the Brain: An Essential Alliance for Sexual Identity and Sexual Orientation." Pediatric Neuroendocrinology. Eds. Sandro Loche et al. Basel: Karger, 2010. 22-35.

Grosz, Elisabeth. Volatile Bodies: Toward a Theory of Corporeal Feminism.

Bloomington: Indiana UP, 1994.

Halberstam, Judith. In a Queer Time and Place. New York, London: New York UP, 2005.

Henry, Todd A. "Between Surveillance and Liberation. The Lives of Cross-

Dressed Male Sex Workers in Early Postwar Japan." Stryker and Aizura 2013. 403-17.

Heyes, Cressida. "Feminist Solidarity after Queer Theory: The Case of Transgender." Stryker and Aizura 2013. 201-12.

Hird, Myra J. “Animal Trans.” Stryker and Aizura 2013. 156-67.

Horlacher, Stefan, ed. Configuring Masculinities in Theory and Literary Practice. Boston and Leiden: Brill/Rodopi, 2015.

. "Towards Comparative Masculinity Studies: On the Interdependence of National Identity and the Construction of Masculinity." Post World War II Masculinities in British and American Literature and Culture: Towards Comparative Masculinity Studies. Eds. Stefan Horlacher and Kevin Floyd. Surrey: Ashgate, 2013. 1-15.

. "Charting the Field of Masculinity Studies; or, Towards a Literary History of Masculinities." Constructions of Masculinity in British Literature from the Middle Ages to the Present. Ed. Stefan Horlacher. New York: Palgrave Macmillan, 2011. 3-18.

. "Überlegungen zur theoretischen Konzeption männlicher Identität: Ein

Forschungsüberblick mit exemplarischer Vertiefung." "Wann ist die Fran eine Frau?" - "Wann ist der Mann ein Mann?" Konstruktionen von Geschlechtlichkeit von der Antike bis ins 21. Jahrbundert. Ed. Stefan Horlacher. Würzburg: Königshausen \& Neumann, 2010. 195-238.

."“... and he took it literally' - Literatur als Instrument der Lebenskunst. Konzeptionen (in)adäquater Lektüre in Thomas Hardys Roman Jude the Obscure." Literatur und Lebenskunst. Reflexionen zum 'guten Leben' im britischen Roman des 19. und 20. Jahrbunderts. Eds. Stefan Horlacher et al. Trier: WVT, 2008. 139-74.

. "Literatur und die Überwindung der Dichotomien. Zum Verhältnis von Lebenswelt, Men's Studies, Gender Studies und savoir littéraire." Literarische 
Final edited form was published in "Transgender and Intersex: Theoretical, Practical, and Artistic Perspectives",

New York: Palgrave Macmillan 2016

https://doi.org/10.1057/978-1-349-71325-7_1

Gendertheorie. Eros und Gesellschaft bei Proust und Colette. Eds. Ursula LinkHeer, Ursula Henningfeld and Fernand Hörner. Bielefeld: Transcript, 2006. 33-56.

. "Daniel Martin, America, Faith in Fakes/Travels in Hyperreality und das

Verschwinden der Realität - Überlegungen zum antizipatorischen Potential von Literatur." Beyond Extremes. Reflexion und Repräsentation von Modernisierungsprozessen im zeitgenössischen britischen Roman. Eds. Stefan Horlacher and Stefan Glomb. Tübingen: Gunter Narr, 2004. 291-329.

Hughes, I. A. "Intersex." BJU International: Journal of the British Association of Urological Surgeons 90 (2002): 769-76.

Iser, Wolfgang. "Ist der Identitätsbegriff ein Paradigma für die Funktion der Fiktion?" Identität. Eds. Odo Marquard and Karlheinz Stierle. München: Wilhelm Fink, 1979. 725-29.

$5-15$.

Jagose, Annamarie. "Masculinity without Men. Annamarie Jagose Interviews Judith Halberstam about Her Latest Book Female Masculinity." Genders 29 (1999): n. pag. Web. 12 Feb 2013. http://www.genders.org/g29/g29_halberstam.html\% 20 .

James, Ian. The Fragmentary Demand: An Introduction to the Philosophy of JeanLuc Nancy. Stanford: Stanford UP, 2006.

Karkazis, Katrina. Fixing Sex: Intersex, Medical Authority, and Lived Experience.

Durham: Duke UP, 2008.

Kunzel, Regina. "The Flourishing of Transgender Studies." TSQ: Transgender Studies Quarterly 1.1-2 (2014): 285-97.

Love, Heather. "Queer." TSQ: Transgender Studies Quarterly 1.1-2 (2014): 172-76.

Matus, Jill L. Unstable Bodies. Victorian Representations of Sexuality and Maternity. Manchester: Manchester UP, 1995.

McKenna, Wendy, and Suzanne Kessler. "Transgendering. Blurring the Boundaries of Gender." Handbook of Gender and Women's Studies. Eds. Kathy Davis, Mary Evans, and Judith Lorber. London: SAGE, 2006. 342-54.

Morland, Iain. "Intersex." Transgender Studies Quarterly 1.1-2 (2014): 111-15. Nancy, Jean-Luc. The Inoperative Community. Minneapolis: U of Minnesota P, 1991.

Noble, Bobby. "Trans. Panic: Some Thoughts toward a Theory of Feminist Fundamentalism." Enke 2012. 45-59.

Prosser, Jay. Second Skins: The Body Narratives of Transsexuality. New York: Columbia UP, 1998.

"Race and Transgender." Feminist Studies 37.2 (2011). Special Issue.

Reeser, Todd W. "Concepts of Masculinity and Masculinity Studies." Horlacher 2015. 11-38. 
Final edited form was published in "Transgender and Intersex: Theoretical, Practical, and Artistic Perspectives",

New York: Palgrave Macmillan 2016

https://doi.org/10.1057/978-1-349-71325-7_1

Singer, T. Benjamin. "From the Medical Gaze to Sublime Mutations. The Ethics of (Re)Viewing Non-normative Body Images." Stryker and Whittle 2006. 601-20.

Stone, Sandy. "The Empire Strikes Back: A Posttranssexual Manifesto." Stryker and Whittle 2006. 221-35.

Stryker, Susan. "Biopolitics." TSQ: Transgender Studies Quarterly 1.1-2 (2014): $38-42$.

"Introduction. Transgender Studies 2.0." Stryker and Aizura 2013. 1-12. . "(De)Subjugated Knowledges: An Introduction to Transgender Studies." Stryker and Whittle 2006. 1-17.

Stryker, Susan, and Aren Z. Aizura, eds. The Transgender Studies Reader 2. New York and London: Routledge, 2013.

Stryker, Susan, and Paisley Currah. "Introduction." TSQ: Transgender Studies Quarterly 1.1-2 (2014a): 1-18.

—_. "General Editor's Introduction.” TSQ: Transgender Studies Quarterly 1.3 (2014b): 303-7.

Stryker, Susan, and Stephen Whittle, eds. The Transgender Studies Reader. London: Routledge, 2006.

Thomas, Brook. "The Fictive and the Imaginary: Charting Literary Anthropology, or, What's Literature Have to Do with It?" American Literary History 20.3 (2008): 622-31.

Valentine, David. Imagining Transgender. Durham: Duke UP, 2007.

van den Berg, Maria Elizabeth Susanna (Elbie). "Bodies as Open Projects: Reflections on Gender and Sexuality." South African Journal of Philosophy 30.3 (2011): 385-402.

Weisser, Susan Ostrov. Women and Sexual Love in the British Novel, 1740-1880. A "Craving Vacancy." Basingstoke: Palgrave, 1997.

Whittle, Stephen. "Foreword." Stryker and Whittle 2006. xi-xvi.

Williams, Cristan. "Transgender." TSQ: Transgender Studies Quarterly 1.1-2 (2014): 232-4.

Windschuttle, Keith. "Foucault as Historian." Critical Review of International Social and Political Philosophy 1.2 (1998): 5-35.

Zhou, Jiang-Ning, et al. "A Sex Difference in the Human Brain and Its Relation to Transsexuality." Nature 378 (1995): 68-70. 